\title{
Acceptance of Couples' HIV Counseling and Testing among Pregnant Women Attending Antenatal Clinic in Likoni sub-County, Mombasa County, Kenya
}

\author{
Jeniffer Makena Mwongera ${ }^{1 *}$, Shadrack Ayieko Yonge ${ }^{1}$, Joseph Baya Msanzu², \\ Rahma Udu Yussuf ${ }^{2}$
}

\author{
${ }^{1}$ Department of Environment and Health Sciences, Technical University of \\ Mombasa, P.O. Box 90420-80100 Mombasa, Kenya \\ ${ }^{2}$ Department of Pure and Applied Sciences, Technical University of Mombasa P.O. Box \\ 90420-80100 Mombasa, Kenya \\ *Corresponding author's email: jeniffermakena@ymail.com
}

\begin{abstract}
$\mathrm{C}$

ouples' HIV Counseling and Testing (CHCT) is an essential component of an effective response to AIDS pandemic worldwide and serves as an entry point to HIV care and support. However, of HIV infection. This study sought to determine level of acceptance of CHCT among pregnant women attending antenatal care services in Likoni sub-County, Mombasa County, Kenya. A descriptive cross-sectional study design was used with structured questionnaires and an observation checklist to collect data from couples while an interview schedule was used to solicit data from health care workers. Results showed uptake of CHCT in the study area was relatively low (33.5\%). Statistically significant associations were found between CHCT and demographic factors such as education $\left(\chi^{2}=\right.$ 29.54; $\mathrm{p}=0.005)$, marital status $\left(\chi^{2}=12.41 ; \mathrm{p}=0.010\right)$, occupation $\left(\chi^{2}=18.18 ; \mathrm{p}<0.001\right)$, income $\left(\chi^{2}=\right.$ 23.02; $\mathrm{p}<0.001)$. In operation factors, statistically significant associations were found between CHCT and distance to health facility $\left(x^{2}=8.31 ; p=0.040\right)$, means of transport $\left(x^{2}=10.28, p=0.040\right)$, cost of transport $\left(\chi^{2}=10.92 ; \mathrm{p}=0.010\right)$, appropriateness and convenience of time allocated $\left(\chi^{2}=11.88, \mathrm{p}<\right.$, $0.001)$, an individual's working hours per day $\left(\chi^{2}=14.46 ; \mathrm{p}<0.001\right)$, and education/information on CHCT $\left(\alpha^{2}=5.97 ; p=0.020\right)$. In HIV related knowledge, attitude and practice of couples on HIV risk behavior, significant associations were found between $\mathrm{CHCT}$ and prevention of discordant partners from contracting HIV $\left(\chi^{2}=53.71 ; \mathrm{p}<0.001\right)$, helping couples adhere to ART $\left(\chi^{2}=43.34 ; \mathrm{p}<0.001\right)$, helping to reduce morbidity and mortality due to HIV and other opportunistic infections $\left(\chi^{2}=48.66 ; \mathrm{p}\right.$ $<0.001)$, increasing trust among partners $\left(\chi^{2}=45.16 ; \mathrm{p}<0.001\right)$, and increasing marital cohesion among partners $\left(X^{2}=65.78 ; p<0.001\right)$. Logistic regression revealed that determinants of CHCT were significant for married status $(\mathrm{p}<0.001)$, unemployed $(\mathrm{p}=0.020)$, that CHCT increases trust among partners $(\mathrm{p}=$ $0.020)$, and that CHCT increases marital cohesion among partners $(\mathrm{p}=0.001)$. Based on these findings, there is need to improve awareness on CHCT to enhance positive attitudes towards couples testing.
\end{abstract}

Key Words: Antenatal clinic, HIV counselling, Couples testing, Mombasa County, Kenya

\section{Introduction}

Human immunodeficiency virus and acquiredimmunodeficiency syndrome (HIV and AIDS) is still a major health concern worldwide. As by 2018, there were 37.9 million people living with HIV worldwide, of which 36.2 million were adults while 1.7 million were children; only $79 \%$ of all the people living with HIV knew their HIV status (Case et al., 2019). Sexual transmission between heterosexuals remains to be the transcendent mode of HIV transmission in sub-Sahara Africa (Donnell, 2010). This is the region where the HIV and AIDS pandemic is transcendently summed up with most of the infections occurring among heterosexual couples.

HIV testing services (HTS) or Voluntary Counseling and Testing (VCT) takes an essential part in HIV treatment, care and prevention, and has experienced very fast development since its launch. In 2012, the World Health Organization (WHO) suggested that couples or partners of expectant women in antenatal care (ANC) settings should be offered 
VCT with support for mutual disclosure (Osoti et al., 2015). Moreover, antiretroviral therapy (ART) should be offered to HIV positive partners in sero-discordant relationships, regardless of CD4 level (Irungu et al., 2016) in order to reduce HIV transmission to uninfected partners (Heffron et al., 2017).

Offering couples HIV counseling and testing (CHCT) at ANC settings provides many benefits including increasing male participation in ANC services, enhancing communication between couples about safe sex practices (Hailemariam et al., 2020), encouraging men to get tested and to know their HIV status, and preventing new HIV infections (Morfaw et al., 2013). CHCT keeps on being an imperative system for sero-discordant couples to get to HIV treatment as anticipation, whereby tainted accomplices are placed in ART therapy instantly in the wake of testing. CHCT has emerged as an important intervention aimed at preventing the transmission of HIV between sex partners, and cohabiting or married couples (World Health Organization, 2012). HIV prevention counselors can assist couples by mitigating tension and diffusing blame, providing clear and accurate prevention messages tailored to the couple's life stage and reasons for seeking $\mathrm{CHCT}$ services, dispelling myths about HIV transmission, discussing options for disclosure of HIV status to the couple's children, and thinking through appropriate next steps for testing children, when necessary, creating an environment that is safe for disclosure of HIV status among partners.

According to Government of Kenya (2016), there were 1,360,819 antenatal labour and delivery clients in Kenya who were tested for HIV out of these, only 63,164 male partners were tested and 2,263 were discordant couples. In Mombasa County, 57,648 mothers attended antenatal services and only 4,455 male partners were tested as couples. Out of the couples tested, 61 were discordant couples. Despite CHCT being a national guideline, few pregnant women come with their spouses for testing. In the year 2016, Mombasa County had a total of 32,419 pregnant women who attended antenatal clinic, out of which 4,455 were tested as couples, 1,998 turned out to be HIV positive and 61 were discordant couples (Government of Kenya, 2017). Likoni sub-County had a total of 4,946 pregnant women who attended antenatal clinic and 742 were tested as a couples while 4,204 were tested alone (Government of Kenya, 2017). Therefore, there is great need to assess the acceptance of couple's HIV counseling and testing and find out what hinders male partners from accessing this important service that can reduce HIV transmission and an excellent component of elimination of mother to child transmission (EMTCT).

\section{Materials and Methods}

The Study Area

The study was conducted in Likoni subCounty, one of the four sub-counties of Mombasa County, Kenya. Mombasa County covers an area of approximately $229.7 \mathrm{~km}^{2}$ excluding $65 \mathrm{~km}^{2}$ of water mass with a population of 1.3 million people, $60 \%$ living in informal settlement (Akunga, 2015). HIV prevalence is $7.4 \%$ with a HIV burden of 54,600 persons annually and HIV incidence of 1,606 persons (Kenya National Bureau of Statistics, 2019). Likoni sub-County is densely populated with a population of 200,000 people (Kenya National Bureau of Statistics, 2019). The socioeconomic status of people living in Likoni subCounty is low, hence poverty and drug abuse has increased HIV and AIDS prevalence rate to 4\% (Kenya National Bureau of Statistics, 2019). The study was conducted in six government health facilities in Likoni sub-County that offer ANC services: Likoni sub-County Hospital, Mrima Health Centre, Mbuta Health Centre, NYS Dispensary, Shika -Adabu Dispensary, and Mtongwe Health Centre.

\section{Research Design}

A cross-sectional descriptive study design was adopted which involved collection of quantitative information that was tabulated along a continuum in numerical form and categories of information described such as gender or patterns of interaction in a group situation.

\section{Study Population}

The study targeted only pregnant women and their partners visiting antenatal clinic at Likoni sub-County hospitals. The inclusion criteria were; only expectant women visiting antenatal clinic and their partners who consented, all pregnant women who had stayed in Likoni for the last six months, and all pregnant women who were 14-45 years old. Nurses in-charge of antenatal clinics in the six facilities were also included. 
The study excluded women who had come for VCT service and were not expectant, pregnant women who had not stayed in Likoni for the last six months, and expectant women who declined to participate in the study. In-charges of antenatal clinic who declined to participate in the study were also excluded.

\section{Sample Size Determination}

The sample size was determined using the formula adopted by Fisher et al., (1998):

$$
\mathrm{n}=\frac{z^{2} p q}{d^{2}}
$$

Where;

$\mathrm{n}=$ the desired sample size (when target population $>10,000$ );

$\mathrm{z}=$ the standard deviation value at $95 \%$ confidence interval (1.96);

$\mathrm{p}=$ the proportion of the study population estimated to have attended CHTC (0.5);

$\mathrm{q}=$ the proportion of the study population estimated not to have attended CHTC (1p), and

$\mathrm{d}=$ degree of precision chosen for the study (0.05).

Therefore;

$$
\mathrm{n}=\frac{(1.96)^{2}(0.5)(0.5)}{(0.05)^{2}}=384
$$

From the health records of all the sub-county hospitals a total of 5,000 pregnant women and their partners were visiting the antenatal clinic, and this made the target population for this study. Since the target population is $<10,000$, the Cochran (1977) formula for calculating a finite population was adopted. Hence, the final sample size was given by the formula:

$$
\begin{aligned}
& \mathrm{n}=\frac{n_{0}}{1+\frac{\left(n_{0}-1\right)}{N}} \\
& \ldots \ldots \ldots \ldots \ldots \ldots \ldots \ldots \ldots \ldots \ldots \ldots \ldots \ldots \ldots \ldots \ldots \ldots \ldots \ldots \ldots \\
& \ldots \ldots \ldots
\end{aligned}
$$

Therefore,

$$
\mathrm{n}=\frac{384}{1+\frac{(384-1)}{5000}}=356.68 \approx 357
$$

Proportionate to size sampling was then used to determine the sample to be picked from each health facility as a proportion of pregnant women in each health facility (Table 1).

Table 1. Number of participants sampled from each health facility based on proportion to size sampling in Likoni sub-County hospitals

\begin{tabular}{llccc}
\hline No. & Health Facility & Total target population & Sample size & \% Sample size \\
\hline 1 & Mbuta Health Centre & 830 & 59 & 16.5 \\
2 & Shika-Adabu Health Centre & 480 & 34 & 9.5 \\
3 & Mtongwe Health Centre & 338 & 24 & 6.7 \\
4 & NYS Dispensary & 42 & 3 & 0.8 \\
5 & Likoni Sub County Hospital & 1370 & 98 & 27.5 \\
6 & Mrima Health Centre & 1940 & 139 & 38.9 \\
\hline & Total & $\mathbf{5 0 0 0}$ & $\mathbf{3 5 7}$ & $\mathbf{1 0 0}$ \\
\hline
\end{tabular}

Sampling Technique

Likoni sub-County was purposively selected because of its reported high cases of discordant couples. The sampling frame consisted of six health facilities within the study area. Cluster sampling technique was employed to draw respondents from the six health facilities. Based on average monthly attendance of the couples in each facility, each study site was allocated a proportionate number of study subjects. Random sampling technique was then used to get the respondents to be interviewed in each health facility during each visit.

\section{Data Collection Process}

A total of six HTS nurses and community health volunteers based in the six health facilities assisted in the data collection process. Prior to their involvement, they were briefed on the aim and objectives of the study. Data collection was carried out during the day at the time convenient for the clients, and as they visited the health facility.

The clients (couples) were approached and informed about the nature of the study and 
taken through a Participant Information Sheet detailing the aim of the study, and issues of Consent and Confidentiality discussed. The couples who agreed to participate were then taken through a structured pretested questionnaire, and their responses recorded accordingly. The questionnaire comprised of questions on socio-demographic characteristics, operation factors, and knowledge, attitude and practices of couples on HIV risk behaviors.

The staff working in antenatal clinic in the six public facilities were interviewed using Interview Schedule. The questions were geared towards supplementing and complementing the information obtained from the couples. An Observation Schedule was used to record the flow of the clients (pregnant women and their spouses), how they were relating with health care workers, duration they took in the facility, and any other information from the facility that supported the study objectives. The reliability of the study tools was enhanced through repeated field tests during pre-testing.

\section{Data Analysis}

The completed questionnaires were checked for missing data, cleaned for inconsistencies and missing values, and then coded and entered into the EpiData (Version 3.1). The data was then exported to $R$ (Version 3.6.1) for further cleaning, coding and analysis. Univariate descriptive statistics was used to analyze each single variable and the findings reported as frequencies. The Chi-square statistical test was used to determine significant associations at $95 \%$ confidence intervals. The bivariate analysis was used to compare the relationship between CHCT. Multivariate logistic regression analysis was performed to determine the odds ratio of the individual predictor factors to CHCT. P value $<0.05$ was regarded as statistically significant.

\section{Results}

Socio-demographic Factors

A total of 321 from the expected 357 respondents were interviewed. The largest proportion $(60 \%)$ of the respondents were aged between 36 and 45 years and only $4.3 \%$ of the respondents were above 45 years old. Majority $(55.8 \%)$ of the respondents had acquired school education, with slightly more than half of them (55.8\%) having completed primary school while $32.1 \%$ and $4.9 \%$ having completed secondary school and college/tertiary education, respectively. Only $7.2 \%$ of the respondents had not acquired school education.

Most of the participants who accepted CHCT attended Mbuta Health Centre (83.9 \%) with majority of those who rejected it having attended Likoni sub-County Hospital (47.5 \%). The majority $(84.7 \%)$ of the respondents were married followed by those who were divorced $(11.6 \%)$, single $(2.6 \%)$ and widowed $(1.2 \%)$. Most respondents belonged to the Islamic religion $(64.4 \%)$ and the rest were Christians $(35.6 \%)$. In terms of occupation, slightly more than a quarter were self-employed (47.3\%) followed by those unemployed (33\%), employed (18\%) and students who made up $1.7 \%$. It was also observed that the majority $(63.3 \%)$ of the respondents were low-income earners, earning a monthly income of between \$ 9.12 - \$ 45.58 (63.3\%).

Chi-square analysis at $5 \%$ significance level ( $p$ $<0.05$ ) revealed statistically significant associations between $\mathrm{CHCT}$ and the following socio-economic factors: education level $\left(\chi^{2}=\right.$ 29.540; $\mathrm{p}=0.005)$, marital status $\left(\chi^{2}=12.410 ; \mathrm{p}=\right.$ $0.010)$, occupation $\left(\chi^{2}=18.180 ; \mathrm{p}=0.000\right)$ and income level $\left(\chi^{2}=23.020, p<0.001\right)$ (Table 2). 
Table 2. Results of Chi-square test on association between socio-demographic factors and acceptance of CHCT among pregnant women attending antenatal clinic at Likoni sub-County, June 2019. *Statistically significant at 5\% confidence level

\begin{tabular}{|c|c|c|c|}
\hline \multirow{2}{*}{ Characteristic } & \multicolumn{2}{|c|}{ CHCT Acceptance Status } & \multirow[b]{2}{*}{ Chi-square, p-value } \\
\hline & $\begin{array}{l}\text { Acceptors } \\
(\%)\end{array}$ & $\begin{array}{l}\text { Non-acceptors } \\
(\%)\end{array}$ & \\
\hline $\begin{array}{l}\text { Age in years }(n=346) \\
15-24 \\
26-35 \\
36-45 \\
\text { Above } 45\end{array}$ & $\begin{array}{l}43.9(n=29) \\
38.6(n=22) \\
29.9(n=58) \\
46.7(n=7)\end{array}$ & $\begin{array}{l}56.1(\mathrm{n}=37) \\
61.4(\mathrm{n}=35) \\
72.1(\mathrm{n}=150) \\
53.3(\mathrm{n}=8)\end{array}$ & $x^{2}=8.00, p=0.770$ \\
\hline $\begin{array}{l}\text { Education level }(\mathrm{n}=346) \\
\text { No education } \\
\text { Primary } \\
\text { Secondary } \\
\text { College/University }\end{array}$ & $\begin{array}{l}48.0(\mathrm{n}=12) \\
43.5(\mathrm{n}=84) \\
16.2(\mathrm{n}=18) \\
11.8(\mathrm{n}=2)\end{array}$ & $\begin{array}{l}52.0(\mathrm{n}=13) \\
66.5(\mathrm{n}=109) \\
83.8(\mathrm{n}=93) \\
88.2(\mathrm{n}=15)\end{array}$ & $x^{2}=29.54, p=0.005^{*}$ \\
\hline $\begin{array}{l}\text { Marital status }(n=346) \\
\text { Single } \\
\text { Married } \\
\text { Divorced } \\
\text { Widowed }\end{array}$ & $\begin{array}{l}33.3(\mathrm{n}=3) \\
30.0(\mathrm{n}=88) \\
57.5(\mathrm{n}=23) \\
50.0(\mathrm{n}=2)\end{array}$ & $\begin{array}{l}66.7(\mathrm{n}=6) \\
70.0(\mathrm{n}=205) \\
42.5(\mathrm{n}=17) \\
50.0(\mathrm{n}=2)\end{array}$ & $\chi^{2}=12.41, p=0.010^{*}$ \\
\hline $\begin{array}{l}\text { Religion }(n=346) \\
\text { Christian } \\
\text { Muslim }\end{array}$ & $\begin{array}{l}35.8(\mathrm{n}=44) \\
32.3(\mathrm{n}=72)\end{array}$ & $\begin{array}{l}64.2(\mathrm{n}=79) \\
67.7(\mathrm{n}=151)\end{array}$ & $x^{2}=0.43, p=0.510$ \\
\hline $\begin{array}{l}\text { Occupation }(\mathrm{n}=346) \\
\text { Unemployed } \\
\text { Self-employed } \\
\text { Employee } \\
\text { Students }\end{array}$ & $\begin{array}{l}47.4(\mathrm{n}=54) \\
30.5(\mathrm{n}=50) \\
17.7(\mathrm{n}=11) \\
16.7(\mathrm{n}=1)\end{array}$ & $\begin{array}{l}52.6(\mathrm{n}=60) \\
69.5(\mathrm{n}=114) \\
82.3(\mathrm{n}=51) \\
83.3(\mathrm{n}=5)\end{array}$ & $x^{2}=18.18, p=0.000^{*}$ \\
\hline $\begin{array}{l}\text { Income (US\$/month) } \\
(\mathrm{n}=226) \\
\$ 9.12-\$ 45.58 \\
\$ 54.69-\$ 91.16 \\
>\quad \$ 91.16\end{array}$ & $\begin{array}{l}46.0(n=23) \\
21.0(n=30) \\
24.2(n=8)\end{array}$ & $\begin{array}{l}54.0(\mathrm{n}=27) \\
79.0(\mathrm{n}=113) \\
75.8(\mathrm{n}=25)\end{array}$ & $x^{2}=23.02, p<0.001$ \\
\hline
\end{tabular}

\section{Operational Factors}

Various operational factors influenced the uptake of CHCT among pregnant women attending ANC at Likoni sub-County (Table 3). Majority of the respondents (49.9\%) reported to reside less than $5 \mathrm{~km}$ from their closest health facility, slightly more than a quarter $(29.2 \%)$ resides $5-10 \mathrm{~km}$ from their closest health facility and $19.4 \%$ resided between $11-15 \mathrm{~km}$; about $2.3 \%$ reported to reside more than $15 \mathrm{~km}$ from their closest health facility.

The main means of transport to the health facility was public transport reported by the majority (54.9\%) with only $0.6 \%$ using private transport. Majority (49.8\%) reported spending between $(\$ 0.46-\$ 0.91)$ as cost of transport to the health facility. Slightly more than half $(57.8 \%)$ of the participants reported that the hours set by the health facilities were not appropriate and convenient to them. Additionally, most of those who were employed (58.1\%) reported that their employers did not allow them to seek medical attention. Similarly, more than half the respondents $(57.2 \%)$ reported to have received enough information from the health care providers on the importance of couples' HIV counselling and testing. Participants who resided more than $15 \mathrm{~km}$ $(62.5 \%)$ from a particular health facility constituted majority of those who accepted CHCT while those who resided $11-15 \mathrm{~km}$ $(76.1 \%)$ constituted a large proportion of participants who did not accept CHCT.

Results of Chi-square test revealed statistically significant association between CHCT and distance to the health facility $\left(x^{2}=\right.$ 8.310; $p=0.040)$, means of transport to the health facility $\left(X^{2}=10.280 ; p=0.040\right)$, cost of 
transport to the health facility $\left(\chi^{2}=10.920, p\right.$ $=0.010)$, appropriateness and convenience of time allocated at the health facility $\left(\chi^{2}=\right.$ $11.880 ; \mathrm{p}=0.000)$, receiving enough education /information on CHCT $\left(\chi^{2}=5.970\right.$; $\mathrm{p}=0.020)$, and duration of work per day $\left(\chi^{2}\right.$ $=14.460 ; \mathrm{p}=0.000)($ Table 3$)$.

Table 3. Results of Chi-square test on operational factors associated with acceptance of couples to HIV counseling and testing among pregnant women attending antenatal clinic in Likoni sub-County, June 2019. *Statistically significant at $5 \%$ confidence level

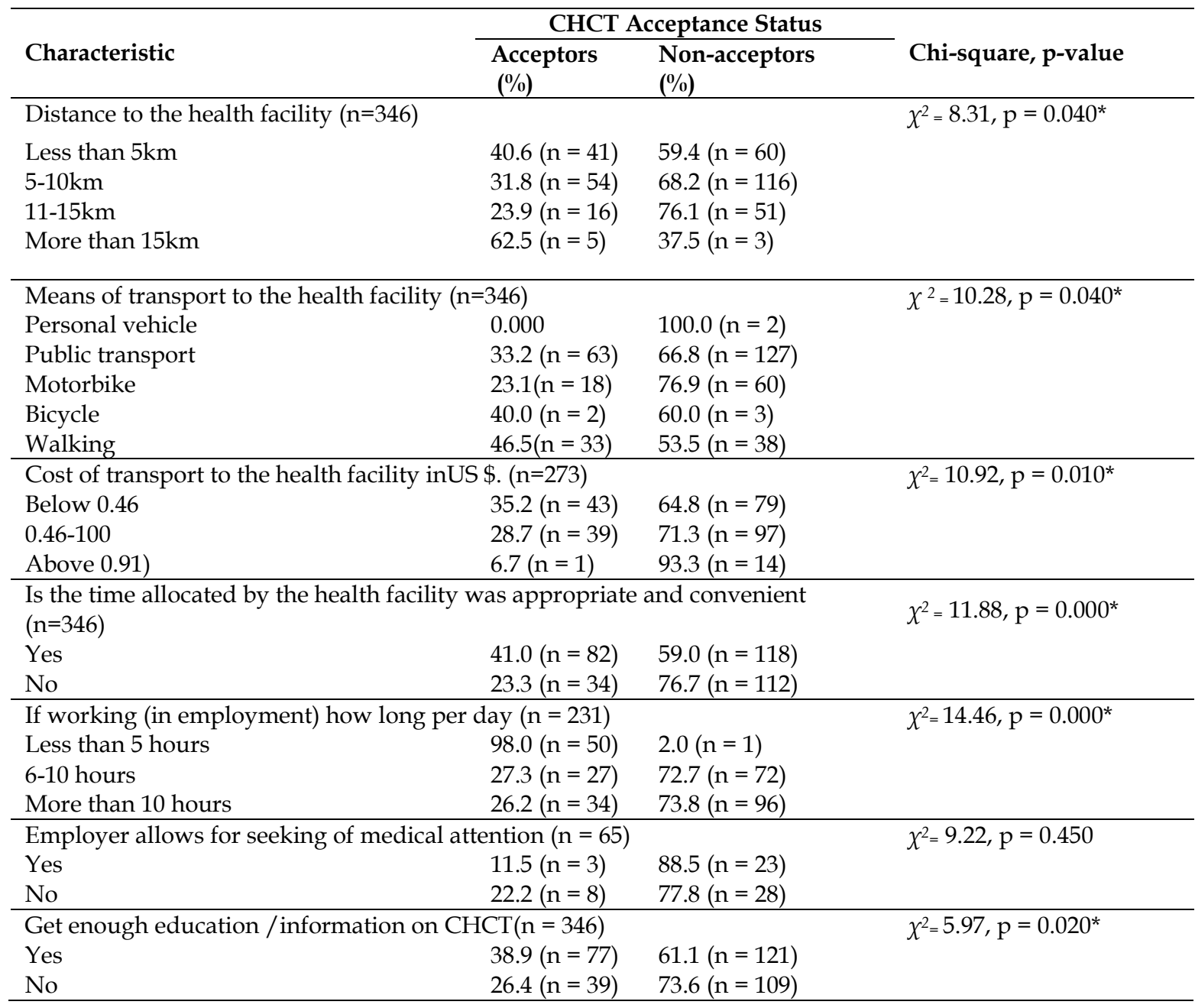

Knowledge, Attitude and Practice of Couples on HIV Risk Behaviours

The associations between CHCT and knowledge, attitude and practice of couples on HIV risk behaviours among pregnant women attending varied (Table 4$)$. Majority $(70.5 \%)$ of the respondents affirmed that $\mathrm{CHCT}$ reduces stigma for the couples and also among family members. A larger proportion (66.2\%) reported that people living with HIV/AIDS were not being discriminated. Almost three quarters of the participants $(71.4 \%)$ acknowledged that CHCT helps in disclosure among partners and also helps the discordant partner from contracting HIV (58.4 \%). It was also reported that CHCT could help the couples adhere to ART $(57.8 \%)$ and also help in reducing morbidity and mortality due to HIV and other opportunistic infections (59.5\%). It was further observed that the uptake of CHCT could increase trust $(58.7 \%)$ and cohesion (61\%) among couples.

Results of Chi-square test showed that a number of variables were statistically significant in the association between the acceptance of CHCT, including; helping to prevent discordant partner from contracting HIV $\left(\chi^{2}=53.710 ; p<0.001\right)$, helping couples adhere to ART $\left(\alpha^{2}=43.340 ; p<0.001\right)$, helping in reducing morbidity and mortality due to HIV and other opportunistic infections $\left(x^{2}=\right.$ 48.660; $\mathrm{p}<0.001)$, help increasing trust among partners $\left(\chi^{2}=41.160 ; \mathrm{p}<0.001\right)$, and help increasing marital cohesion among partners 


$$
\left(\chi^{2}=65.780 ; p<0.001\right)
$$

\section{Determinants of Couples HIV Counselling Testing}

Results of multiple logistic regression analysis on independent predictors against couples' acceptance to HIV counseling and testing varied (Table 5). It was observed that couples who were married were 3.6 more likely to accept CHCT (AOR = 3.590; 95\% CI: 1.71-7.72; $\mathrm{p}=0.000)$ than those who were divorced; the unemployed couples had a reduced odd of $64 \%$ $(\mathrm{AOR}=0.360 ; 95 \%$ CI: $0.15-0.81 ; \mathrm{p}=0.020)$ of accepting CHCT as compared to their counterparts who were employed.
Individual operational factors did not significant determine CHCT. However, for HIV related knowledge, attitude and practice, those who believed that CHCT can help improve trust among partner were 22.82 times more likely to accept CHCT (AOR $=22.820 ; 95 \% \mathrm{CI}$ : 1.76-709.86; $\mathrm{p}=0.020)$ than their counterparts, and those who believed that CHCT increases marital cohesion had reduced odds of $99.6 \%$ (AOR $=0.040 ; 95 \%$ CI: 0.00-0.19; $\mathrm{p}=<0.001)$ of accepting CHCT as compared to their counterparts who did not believe that $\mathrm{CHCT}$ increases marital cohesion.

Table 4. Results of Chi-square test on HIV related knowledge, attitude and practice associated with acceptance of couples to HIV counseling and testing among pregnant women attending antenatal clinic in Likoni sub-County, June 2019. *Statistically significant at $5 \%$ confidence level

\begin{tabular}{|c|c|c|c|}
\hline \multirow[b]{2}{*}{ Characteristic } & \multicolumn{2}{|c|}{ CHCT Acceptance Status } & \multirow[b]{2}{*}{ Chi-square, p-value } \\
\hline & $\begin{array}{c}\text { Acceptors } \\
(\%)\end{array}$ & $\begin{array}{c}\text { Non-acceptors } \\
(\%)\end{array}$ & \\
\hline \multicolumn{3}{|l|}{ CHCT reduces stigma within the couples $(\mathrm{n}=346)$} & \multirow[t]{3}{*}{$\chi^{2}=0.110 ; p=0.740$} \\
\hline Yes & $32.8(\mathrm{n}=80)$ & $67.2(\mathrm{n}=164)$ & \\
\hline No & $35.3(n=36)$ & $64.7(\mathrm{n}=66)$ & \\
\hline \multicolumn{3}{|l|}{ CHCT reduces stigma among family members $(n=346)$} & \multirow[t]{3}{*}{$x^{2}=0.350 ; p=0.560$} \\
\hline Yes & $32.4(\mathrm{n}=81)$ & $67.6(\mathrm{n}=169)$ & \\
\hline No & $36.5(n=35)$ & $63.5(n=61)$ & \\
\hline \multirow{2}{*}{$\begin{array}{l}\text { PLHIV/AIDS are discriminated }(\mathrm{n}=346) \\
\text { Yes } \\
\text { No }\end{array}$} & $29.1(\mathrm{n}=34)$ & $70.9(\mathrm{n}=83)$ & \multirow[t]{2}{*}{$x^{2}=1.580 ; p=0.210$} \\
\hline & $35.8(\mathrm{n}=82)$ & $64.2(\mathrm{n}=147)$ & \\
\hline \multicolumn{3}{|l|}{ CHCT helps in disclosure among partners $(n=346)$} & \multirow{3}{*}{$\chi^{2}=0.700 ; p=0.400$} \\
\hline Yes & $32.0(\mathrm{n}=79)$ & $68.0(n=168)$ & \\
\hline No & $37.4(\mathrm{n}=37)$ & $62.6(n=62)$ & \\
\hline \multicolumn{3}{|c|}{ CHCT can help prevent discordant partner from contracting HIV $(n=346)$} & \multirow{3}{*}{$\chi^{2}=53.710 ; \mathrm{p}<0.001$} \\
\hline Yes & $17.8(n=36)$ & $82.2(n=166)$ & \\
\hline No & $55.6(n=80)$ & $44.4(\mathrm{n}=64)$ & \\
\hline \multicolumn{3}{|l|}{ CHCT can help couples adhere to ART $(n=346)$} & \multirow{3}{*}{$\chi^{2}=43.340 ; \mathrm{p}<0.001$} \\
\hline Yes & $19.0(\mathrm{n}=38)$ & $81.0(n=162)$ & \\
\hline No & $53.4(\mathrm{n}=78)$ & $46.6(n=68)$ & \\
\hline \multicolumn{3}{|c|}{$\begin{array}{l}\text { CHCT can help reduce morbidity and mortality due to HIV and other opportunistic } \\
\text { infections }(n=346)\end{array}$} & \multirow[t]{3}{*}{$\chi^{2}=48.660 ; \mathrm{p}<0.001$} \\
\hline Yes & $18.9(n=39)$ & $81.1(n=167)$ & \\
\hline No & $55.0(\mathrm{n}=77)$ & $45.0(n=63)$ & \\
\hline \multicolumn{3}{|l|}{ CHCT can help increase trust among partners $(n=346)$} & \multirow{3}{*}{$\chi^{2}=45.160 ; \mathrm{p}<0.001$} \\
\hline Yes & $19.2(\mathrm{n}=39)$ & $80.2(n=164)$ & \\
\hline No & $53.8(\mathrm{n}=77)$ & $46.2(n=63)$ & \\
\hline \multicolumn{3}{|c|}{ CHCT can help increase marital cohesion among partners $(n=346)$} & \multirow[t]{3}{*}{$\chi^{2}=65.780 ; p<0.001$} \\
\hline Yes & $17.1(\mathrm{n}=36)$ & $82.9(\mathrm{n}=175)$ & \\
\hline No & $40.7(n=55)$ & $59.3(\mathrm{n}=80)$ & \\
\hline
\end{tabular}


Table 5. Results of regression analysis for independent predictors of couples' acceptance to HIV counseling and testing in Likoni sub-County, June 2019. *Statistically significant at 5\% confidence level

\begin{tabular}{|c|c|c|}
\hline Characteristic & Adjusted Odds Ratio (95 \% CI) & P-value \\
\hline \multicolumn{3}{|c|}{ Socio-demographic characteristics } \\
\hline \multicolumn{3}{|c|}{ Education level } \\
\hline No education & Ref & - \\
\hline Primary & $0.22(0.01-1.86)$ & 0.220 \\
\hline Secondary & $0.17(0.01-1.17)$ & 0.130 \\
\hline Tertiary/college & $0.52(0.03-3.57)$ & 0.570 \\
\hline \multicolumn{3}{|l|}{ Marital status } \\
\hline Married & $3.59(1.71-7.72)$ & $0.000^{*}$ \\
\hline Single & $3.64(0.72-21.57)$ & 0.130 \\
\hline Widowed & $1.55(0.17-14.12)$ & 0.680 \\
\hline Divorced & Ref & - \\
\hline \multicolumn{3}{|l|}{ Occupation } \\
\hline Self-employed & $0.94(0.4-2.1)$ & 0.880 \\
\hline Student & Ref & - \\
\hline Unemployed & $0.47(0.02-14.33)$ & 0.630 \\
\hline Employed & $0.36(0.15-0.81$ & $0.020^{*}$ \\
\hline \multicolumn{3}{|l|}{ Operational factors } \\
\hline \multicolumn{3}{|c|}{ Distance to the health facility } \\
\hline Less than $5 \mathrm{~km}$ & $1.75(0.5-6.66)$ & 0.390 \\
\hline $5-10 \mathrm{~km}$ & $0.93(0.32-2.52)$ & 0.880 \\
\hline $11-15 \mathrm{~km}$ & $0.31(0.05-1.75)$ & 0.190 \\
\hline More than $15 \mathrm{~km}$ & Ref & - \\
\hline \multicolumn{3}{|c|}{ Means of transport to the health facility } \\
\hline Personal vehicle & - & - \\
\hline Public transport & $3.12(0.27-34.59)$ & 0.340 \\
\hline Motorbike & $3.08(0.31-27.85)$ & 0.310 \\
\hline Bicycle & Ref & - \\
\hline Walking & $1.64(0.18-13.4)$ & 0.640 \\
\hline \multicolumn{3}{|c|}{ Cost of transport to the health facility in Ksh. } \\
\hline Below 50 & $0.98(0.5-1.93)$ & 0.960 \\
\hline $50-100$ & $4.9(0.87-92.68)$ & 0.140 \\
\hline Above 100 & Ref & - \\
\hline \multicolumn{3}{|c|}{$\begin{array}{l}\text { Time allocated by the health facility was appropriate and } \\
\text { convenient }\end{array}$} \\
\hline Yes & $0.57(0.67-1.2)$ & 0.140 \\
\hline No & Ref & - \\
\hline \multicolumn{3}{|c|}{ If working (in employment, working hrs day } \\
\hline Less than 5 hours & $0.57(0.02-15.52)$ & 0.710 \\
\hline 6-10 hours & $1.47(0.71-3.06)$ & 0.300 \\
\hline More than 10 hours & Ref & - \\
\hline \multicolumn{3}{|c|}{ Get enough education/information on CHCT } \\
\hline Yes & $0.85(0.43-1.68)$ & 0.630 \\
\hline No & Ref & - \\
\hline \multicolumn{3}{|c|}{ HIV related knowledge, attitude and practice } \\
\hline \multicolumn{3}{|c|}{ CHCT can help prevent discordant partner from contracting } \\
\hline \multicolumn{3}{|c|}{ HIV } \\
\hline Yes & $028(0.07-1.04)$ & 0.060 \\
\hline No & Ref & - \\
\hline \multicolumn{3}{|c|}{ CHCT can help couples adhere to ART } \\
\hline Yes & $1.29(0.25-10.52)$ & 0.780 \\
\hline No & Ref & - \\
\hline \multicolumn{3}{|c|}{$\begin{array}{l}\text { CHCT can help reduce morbidity and mortality due to HIV and } \\
\text { other opportunistic infection }\end{array}$} \\
\hline Yes & $0.45(0.03-4.72)$ & 0.510 \\
\hline No & Ref & - \\
\hline \multicolumn{3}{|c|}{ CHCT can help increase trust among partners } \\
\hline Yes & $22.82(1.76-709.86)$ & $0.020^{*}$ \\
\hline No & Ref & - \\
\hline
\end{tabular}


CHCT can help increase marital cohesion among partners

Yes

No

\section{Discussion}

The World Health Organization (WHO) guidelines recommend offering of HIV testing and counseling to couples wherever HIV testing and counseling is available (World Health Organization, 2012). In regards to couples where only one partner is HIV positive, the guidelines recommend offering of antiretroviral therapy to the HIV positive partner, regardless of his/her own immune status, so as to reduce the likelihood of HIV transmission to the HIV negative partner (Donnell et al., 2010). This study observed that in Likoni sub-County, 33.5\% of the respondents had accepted CHCT, a proportion that is slightly higher than that recorded in the 2012 Kenya AIDS Indicator Survey (NASCOP, 2014) which observed a national CHCT rate of $31.5 \%$. However, found the CHCT in Kenya to be $37.2 \%$. Nannozi et al., (2017), in their study which determined motivators of CHCT uptake in a rural setting in Uganda, observed an uptake of $34.0 \%$.

Couples HIV testing and counseling is a welltested, feasible, and acceptable intervention that reduces HIV transmission through serostatus based counseling (Banje et al., 2016). The present study has shown that several sociodemographic factors were significantly and independently associated with acceptance of CHCT. Socio-demographic factors such as location of the health facility, education status, marital status, occupation and income were significantly associated with $\mathrm{CHCT}$ acceptance among the respondents. However, results of multivariate logistic regression analysis showed that only couples who were married and those who were unemployed were significant determinants of CHCT. Kababu et al., (2018) reported that, married couples and those in stable sexual relationships account for the highest percentage $(44 \%)$ of new HIV infections. Nannozi et al., (2017) in their study pointed out that HIV testing was a prerequisite in many churches in Uganda before wedding. Thus, this idea of HIV testing was also extended among the individuals who intended to commit to a serious relationship. Hlongwa et al., (2020) reported that married men are more likely to go for CHCT compared to those who are cohabiting or are in a stable heterosexual relationship, who may not think that $\mathrm{CHCT}$ was important or may be afraid of the outcome of the HIV test results. Also, it could be that these men are not as committed to the relationship as married men for them to ask the partner to go for CHCT, or it could be that they may have had individual HIV counseling and testing so they already know their status. On the other hand, in this present study, an individual's occupation and amount of income earned were also observed to be a significant determinant to accepting CHCT.

The unemployed respondents formed a larger proportion of those who accepted CHCT in the present study. Our verification with all the sampled health facilities in this study showed that, the unemployed group formed the vast majority of those who seek health care from these facilities. The only reasonable explanation we could give for this trend is that, all of these health facilities sampled were public health facilities; thus, this group could easily afford most of the services offered.

The acceptance of CHCT in this study was also associated with variety of operational factors such as distance to the health facility, mode and cost of transport to the health facility. It was noted that when distance to the health facility was more than $15 \mathrm{~km}$, mode of transport became difficult and fares increase and the proportion of CHCT acceptors tended to decline tremendously. When the health facility is near, one is able to seek medical services from the facility but when it is located far an individual may opt for other alternatives such as traditional herbalist. that the observed highest response rate of $38.2 \%$ of CHCT at Mrima Health Centre was due to the fact that the health facility was new and under support of other stakeholders (Médecins Sans Frontiéres) that was giving a token to the clients who visited the facility. The facility also doubled up to be the maternity hospital offering reproductive health services only for free. Additionally, being a new facility, many would wish see the services offered by the donors (the French). NYS dispensary, has restrictions and controls for external clients 
since it was built specifically for National Youth Service staff. It also has accessibility issues since it is not near to the public, one has to walk a long distance. Multivariate analysis did not reveal any operational factor as a statistically significant determinant to CHCT.

Adversary to the difficulty on the mode of transport and fare paid by pregnant women so as to attend a particular health facility has been highlighted in other studies. Konje et al., 2018) highlighted on the factors associated with HIV testing and counselling among couples in Bulawayo City and noted that short distances were associated with a high CHCT uptake. Additionally, Shifraw et al., (2016) in their study why women preferred home births in Ethiopia reported found out that most pregnant women tend not to utilize the services of health facility when they are located far away. Laurenzi et al., (2020) stated that most pregnant women are not able to access transport services due to the poor road network and infrastructure especially in rural and poor urban regions in Africa. Similarly, Chandia et al., 2017) reported that availability of affordable transport and the condition of the roads influences the decision to attend a service at a health facility. Availability of time for couples to attend HIV testing and counseling has also been linked to a high CHCT uptake (Muhindo et al., 2015). In the present study the findings showed that, time allocated for patients by a particular health facility also tends to encourage more couple to attend HIV counseling and testing together. Where the time allocation is convenient and appropriate, more couples seem to attend the process together. Similarly, in instances where the working duration increases for the employed individuals, the proportion of those accepting CHCT tend to be low.

CHCT helped in creating trust among couples, knowing the HIV status one's partner and fosters cohesion/unity among the couples. These benefits are relevant for all couples, whether they have the same HIV test results (HIV sero-concordant) or have different results (HIV sero-discordant). Several studies suggest that people who learn their HIV status are more likely to adopt preventive behaviours than people who are unaware of their HIV status. Furthermore, couples who test together and mutually disclose their HIV status are more likely than those testing alone to adopt behaviour to protect their partner (Masters et al., 2016).

Education level has been reported in several settings as a main factor for creating a firsthand knowledge and awareness. A good proportion of the study participants in the present study affirmed that they are well versed with CHCT knowledge. Chamie et al., (2014) reported that peer education is an eminent intervention that can increase knowledge and positive attitudes towards HIV/AIDS among adolescents. Additionally, among people living with HIV, knowledge of HIV status has been associated with more than $60 \%$ reduction in HIV transmission through improved risk-reduction behavior (O'Connell et al., 2015). There are many potential benefits for supporting couples to test together for HIV infection, and to mutually disclose their HIV status. Through testing together, they can then make informed decisions about HIV prevention and reproductive health (Tabana et al., 2013).

The benefits of CHCT have been pointed out in other studies such as safer sexual behaviour in couples who use condoms (Muhindo et al., 2015), higher uptake of interventions such as antiretroviral therapy (ART) for HIV-positive partners (McNairy et al., 2013), reduction in HIV incidence among HIV-negative sex partners and viral load among HIV-positive partners increased knowledge of CHCT (Nannozi et al., 2017). The present study observed that, couples who failed to disclose their status to their partners may experience poor adherence to appointments dates/drugs due to fear of the other partner (mostly fear from their male partners), poor clinical followup and difficulty in treatment. Thus, it is essential that the providers of CHTC should adhere to basic tenets of self-determination, privacy, informed decision-making and protection.

Despite the aforementioned benefits, participants also highlighted certain barriers that influenced couples not to attend HIV counseling and testing together. Stigma, fear, feeling that it is not necessary, and couples not yet decided to do so, were some of the barriers which made the respondents in the present study opt not to attend CHCT. This finding concurs with the WHO (2012) findings that, stigma and discrimination were significant problems for people with HIV. Moreover, 
findings of this study concur with studies such as (O'Connell et al., 2015) who observed that, the barriers to low uptake of CHTC include fear of negative outcomes of disclosure, conflicting work schedules, unwillingness of partner to test, low risk perception of HIV infection, prior testing of HIV, marital status and lack of CHTC awareness. Nannozi et al., (2017) reported mistrust among couples and limited men involvements are also some of the barriers to CHCT uptake. Ammon et al., (2018) pointed out that, the main barriers to HIV counseling and testing among male partners include stigma, fear of prognosis, lack of awareness of HIV risk, inconvenience, fear of disclosure, transportation costs, opportunity costs such as time away from work, and behavioral factors such as a tendency to delay behaviors with immediate costs and delayed benefits.

\section{Conclusion and Recommendation}

The uptake of CHCT in the study area is still low. The location of the health facility, mode of transport and cost of transport to health facility; educational status; marital status; occupation and amount of income earned; availability of time to attend health facility; awareness of CHCT were some of the factors that could positively affect uptake. Further work is needed to determine the quality of a particular health facility and services offered by these facilities to promote CHCT uptake.

\section{Acknowledgement}

The authors acknowledge the support of the staff at the six health facilities in Likoni subCounty, and the respondents for making this study successful. Much gratitude also extended to the lecturers in the Department of Environment and Health Sciences, Technical University of Mombasa for their much needed support and guidance in making this study a success.

\section{References}

Akunga, B.G. (2015). Influence of climate variability on coastal small-scale fishing communities in Kenya. PhD thesis, School of Environmental Studies, Kenyatta University, Kenya. 237pp

Ammon, N., Mason, S. \& Corkery, J. M. (2018). Factors impacting antiretroviral therapy adherence among human immunodeficiency virus-positive adolescents in sub-Saharan Africa: a systematic review. Public Health 157: 20-31

Banje, Y.M. (2016). Perceived stigmatization, social support, gender and educational level on self-disclosure of HIV/AIDS status among PLWHA in JOS. PhD thesis, Benue State University, Makurdi. 124pp

Case, K.K., Johnson, L.F., Mahy, M., Marsh, K., Supervie, V. \& Eaton, J.W. (2019). Summarizing the results and methods of the 2019 Joint United Nations Programme on HIV/AIDS HIV estimates. AIDS (London, England), 33(Suppl 3): S197

Chandia, J. (2017). The experiences of HIV positive patients on antiretroviral drugs attending the public service health institutions in the Eastern Cape Province: A qualitative study. PhD thesis, University of Stellenbosch, South Africa. 210pp

Chamie, G., Kwarisiima, D., Clark, T.D., Kabami, J., Jain, V., et al. (2014). Uptake of Community-Based HIV testing during a multi-disease health campaign in rural Uganda. PLoS ONE 9(1): e84317

Donnell, D., Baeten, J. M., Kiarie, J., Thomas, K. K., Stevens, W., Cohen, C. R. \& Partners in Prevention HSV/HIV Transmission Study Team. (2010). Heterosexual HIV1 transmission after initiation of antiretroviral therapy: a prospective cohort analysis. The Lancet 375(9731): 2092-2098

Government of Kenya (2016). District Health Information System (DHIS2). Ministry of Health, Nairobi

Government of Kenya (2017). District Health Information System (DHIS). Ministry of Health, Nairobi

Hailemariam, T.G., Rawstorne, P., Sisay, M.M., \& Nathan, S. (2020). Beliefs and intention of heterosexual couples about undertaking Couple's HIV Testing and Counselling 
(CHTC) services in Ethiopia. BMC Health Services Research 20(1): 1-14

Heffron, R., Ngure, K., Odoyo, J., Bulya, N., Tindimwebwa, E., Hong, T., \& Team, T.P.D.P. (2017). Pre-exposure prophylaxis for HIV-negative persons with partners living with HIV: uptake, use, and effectiveness in an open-label demonstration project in East Africa. Gates Open Research 1

Hlongwa, M., Mashamba-Thompson, T., Makhunga, S. \& Hlongwana, K. (2020). Barriers to HIV testing uptake among men in sub-Saharan Africa: a scoping review. African Journal of AIDS Research 19(1): 13-23

Irungu, E.M., Heffron, R., Mugo, N., Ngure, K., Katabira, E., Bulya, N. \& Baeten, J.M. (2016). Use of a risk scoring tool to identify higher-risk HIV-1 serodiscordant couples for an antiretroviral-based HIV-1 prevention intervention. BMC Infectious Diseases, 16(1): 1-6

Kababu, M., Sakwa, E., Karuga, R., Ikahu, A., Njeri, I., Kyongo, J. \& Mukoma, W. (2018). Use of a counsellor supported disclosure model to improve the uptake of couple HIV testing and counselling in Kenya: a quasiexperimental study. BMC Public Health, 18(1): 1-10

Kenya National Bureau of Statistics (2019). Kenya Demographic and Health Survey 2014 Report. KEN_2014_DHS_v01_M

Konje, E.T., Magoma, M.T.N., Hatfield, J., Kuhn, S., Sauve, R.S. \& Dewey, D.M. (2018). Missed opportunities in antenatal care for improving the health of pregnant women and newborns in Geita district, Northwest Tanzania. BMC Pregnancy and Childbirth 18(1): 1-13

Laurenzi, C.A., Skeen, S., Coetzee, B.J., Gordon, S., Notholi, V. \& Tomlinson, M. (2020). How do pregnant women and new mothers navigate and respond to challenges in accessing health care? Perspectives from rural South Africa. Social Science \& Medicine 258: 113100

Masters, S. H., Agot, K., Obonyo, B., Napierala Mavedzenge, S., Maman, S., \&
Thirumurthy, H. (2016). Promoting partner testing and couples testing through secondary distribution of HIV self-tests: a randomized clinical trial. PLOS Medicine 13(11): e1002166

McNairy, M.L., Cohen, M., \& El-Sadr, W.M. (2013). Antiretroviral therapy for prevention is a combination strategy. Current HIV/AIDS Reports 10(2): 152-158

Morfaw, F., Mbuagbaw, L., Thabane, L., Rodrigues, C., Wunderlich, A.P., Nana, P., \& Kunda, J. (2013). Male involvement in prevention programs of mother to child transmission of HIV: a systematic review to identify barriers and facilitators. Systematic Reviews 2(1): 1-13

Muhindo, R., Nakalega, A., \& Nankumbi, J. (2015). Predictors of couple HIV counseling and testing among adult residents of Bukomero sub-county, Kiboga District, rural Uganda. BMC Public Health 15(1): 1-6

NASCOP (2014). Kenya AIDS Indicator Survey 2012: Final Report. Ministry of Health Nairobi 159pp

Nannozi, V., Wobudeya, E., Matsiko, N., \& Gahagan, J. (2017). Motivators of couple HIV counseling and testing (CHCT) uptake in a rural setting in Uganda. BMC Public Health 17(1): 1-6

O'Connell, A.A., Reed, S.J., \& Serovich, J.A. (2015). The efficacy of serostatus disclosure for HIV transmission risk reduction. AIDS and Behavior 19(2): 283-290

Osoti, A.O., John-Stewart, G., Kiarie, J.N., Barbra, R., Kinuthia, J., Krakowiak, D. \& Farquhar, C. (2015). Home-based HIV testing for men preferred over clinic-based testing by pregnant women and their male partners, a nested cross-sectional study. BMC Infectious Diseases 15(1): 1-7

Shifraw, T., Berhane, Y., Gulema, H., Kendall, T., \& Austin, A. (2016). A qualitative study on factors that influence women's choice of delivery in health facilities in Addis Ababa, Ethiopia. BMC Pregnancy and Childbirth 16(1): 1-6 
Tabana, H., Doherty, T., Rubenson, B., Jackson, D., Ekström, A.M. \& Thorson, A. (2013). 'Testing together challenges the relationship': Consequences of HIV testing as a couple in a high HIV prevalence setting in rural South Africa. PLoS One 8(6): e66390
World Health Organization. (2012). Male involvement in the prevention of mother-tochild transmission of HIV. World Health Organization. 